\title{
Reactive Power Control using Sine Cosine Algorithm for Active Power Loss Minimization with Voltage Profile Enhancement
}

\author{
R. Ravisekar, K. Srinivasan
}

\begin{abstract}
The major purpose of optimal reactive power dispatch (ORPD) is to detect control variables like the voltage ratings of the generator, switchable shunt condenser banks, and the tap ratio of the tap setting transformer to reduce the active power loss for fixed economic power planning when taking on a set of constraints. This paper introduces the application of the sine cosine algorithm (SCA) to find the novel solution for the reactive power dispatch of power systems with different test systems (Standard IEEE 14-bus, IEEE 57-bus and IEEE 118bus) with specific cases like reducing active power losses and increasing bus voltages in test systems. Obtained results validate the high tone of the proposed algorithm, with better, fast and consistent results comparing with existing literatures.
\end{abstract}

Keywords: Active power loss reduction, Optimal reactive power dispatch, Sine cosine algorithm, Whale optimization algorithm, Ant lion optimizer.

\section{INTRODUCTION}

Optimal reactive power dispatch (ORPD) has recognized boundless consideration in the final few spans and has become a major concern to improve the performance of the power system's budget and safety. ORPD problem, which is a non-linear, non-convex also non-differentiable optimization problem, goals at minimizing the objective functions like voltage improvement [1-3] and system active power losses through the proper control parameters corresponding to generator voltages, switchable reactive sources, tap settings of transformers.

Mathematical algorithms were used in the initial stages to solve ORPD problems such as the Decomposition process, Newton approach, nonlinear programming, interior point Jacobian matrix, etc. [4-7]. These methods solve the objective function by linearzing the objective function. Since the ORPD problem has more than one local optima issues, also, it is a non-linear optimization problem. Therefore, finding the global optimum using mathematical algorithms is so complex. Nonetheless, in that regard, algorithms such as premature convergence and algorithmic complexity have few drawbacks. For these causes heuristic and meta-heuristic algorithms are developed to solve the problem of ORPD in Table 1.
Revised Manuscript Received on December 22, 2019.

R. Ravisekar, Research Scholar, Electrical and Electronics Engineering Dept. Bharath Institute of Higher Education and Research Chennai, 600073

K. Srinivasan, Professor and Head Electrical and Electronics Engineering Dept. Tagore Engineering College, Chennai 600127

Table. 1 Literature review for the solution of ORPD problem

\begin{tabular}{|c|c|c|c|}
\hline Approach & Reference & Objective & Test System \\
\hline IEP & [8] & $\begin{array}{l}\text { Active power } \\
\text { loss }\end{array}$ & $\begin{array}{l}\text { IEEE 118-bus } \\
\text { system and a } \\
\text { realistic power } \\
\text { system in } \\
\text { Western China }\end{array}$ \\
\hline MAPSO & [9] & $\begin{array}{l}\text { Active power } \\
\text { loss }\end{array}$ & $\begin{array}{l}\text { IEEE 30-bus and } \\
\text { IEEE 118-bus }\end{array}$ \\
\hline $\mathrm{DE}$ & [10] & $\begin{array}{l}\text { Active power } \\
\text { loss }\end{array}$ & $\begin{array}{l}\text { IEEE 14, IEEE } \\
\text { 30, and IEEE } \\
118-\text { Bus }\end{array}$ \\
\hline DPSO & [11] & $\begin{array}{l}\text { Active power } \\
\text { loss and } \\
\text { the costs of } \\
\text { adjusting the } \\
\text { control devices }\end{array}$ & IEEE 30-bus \\
\hline SOA & [12] & $\begin{array}{l}\text { Active power } \\
\text { loss }\end{array}$ & $\begin{array}{l}\text { IEEE } 57 \text {-bus and } \\
\text { IEEE 118-bus }\end{array}$ \\
\hline CLPSO & [13] & $\begin{array}{l}\text { Active power } \\
\text { loss and voltage } \\
\text { profile }\end{array}$ & $\begin{array}{l}\text { IEEE } 30 \text {-bus and } \\
\text { IEEE } 118 \text {-bus }\end{array}$ \\
\hline DMSDE & [14] & $\begin{array}{l}\text { Active power } \\
\text { loss }\end{array}$ & $\begin{array}{l}\text { IEEE 30-bus, } \\
\text { IEEE 57-bus and } \\
\text { IEEE 118-bus }\end{array}$ \\
\hline HSA & [15] & $\begin{array}{l}\text { Active power } \\
\text { loss and voltage } \\
\text { profile }\end{array}$ & $\begin{array}{l}\text { IEEE 30-bus and } \\
\text { IEEE 57-bus }\end{array}$ \\
\hline $\begin{array}{c}\text { MNSGA- } \\
\text { II }\end{array}$ & [16] & $\begin{array}{l}\text { Active power } \\
\text { loss and voltage } \\
\text { stability }\end{array}$ & $\begin{array}{l}\text { IEEE 30-bus and } \\
\text { IEEE 118-bus }\end{array}$ \\
\hline $\mathrm{BBO}$ & [17] & $\begin{array}{l}\text { Active power } \\
\text { loss and voltage } \\
\text { profile }\end{array}$ & $\begin{array}{l}\text { IEEE 30-bus and } \\
\text { IEEE 118-bus }\end{array}$ \\
\hline MASRL & [18] & $\begin{array}{l}\text { Active power } \\
\text { loss }\end{array}$ & $\begin{array}{l}\text { Ward-Hale 6- } \\
\text { bus, IEEE 30- } \\
\text { bus and IEEE } \\
\text { 162-bus }\end{array}$ \\
\hline GSA & [19] & $\begin{array}{l}\text { Active power } \\
\text { loss, voltage } \\
\text { profile, and } \\
\text { voltage stability }\end{array}$ & $\begin{array}{l}\text { IEEE 30-bus, } \\
\text { IEEE 57-bus and } \\
\text { IEEE 118-bus }\end{array}$ \\
\hline HDE & [20] & $\begin{array}{l}\text { Active power } \\
\text { loss and voltage } \\
\text { profile }\end{array}$ & $\begin{array}{l}\text { IEEE 30-bus, } \\
\text { IEEE57-bus and } \\
\text { IEEE118-bus }\end{array}$ \\
\hline
\end{tabular}




\begin{tabular}{|c|c|c|c|}
\hline QOTLBO & [21] & $\begin{array}{l}\text { Active power } \\
\text { loss, voltage } \\
\text { profile, and } \\
\text { voltage stability }\end{array}$ & $\begin{array}{l}\text { IEEE 30-bus and } \\
\text { IEEE 118-bus }\end{array}$ \\
\hline HFMOEA & [22] & $\begin{array}{l}\text { Active power } \\
\text { loss and voltage } \\
\text { stability }\end{array}$ & IEEE24-busRTS \\
\hline $\begin{array}{l}\text { HMICA- } \\
\text { IWO }\end{array}$ & [23] & $\begin{array}{l}\text { Active power } \\
\text { loss }\end{array}$ & $\begin{array}{l}\text { IEEE 30-bus, } \\
\text { IEEE 57-bus and } \\
\text { IEEE 118-bus }\end{array}$ \\
\hline OGSA & [24] & $\begin{array}{l}\text { Active power } \\
\text { loss, voltage } \\
\text { profile, and } \\
\text { voltage stability }\end{array}$ & $\begin{array}{l}\text { IEEE 30-bus, } \\
\text { IEEE 57-bus and } \\
\text { IEEE 118-bus }\end{array}$ \\
\hline HFA & [25] & \begin{tabular}{|l|} 
Active power \\
loss and voltage \\
deviation
\end{tabular} & $\begin{array}{l}\text { IEEE 30-bus and } \\
\text { IEEE 118-bus }\end{array}$ \\
\hline $\begin{array}{c}\text { MGBTLB } \\
\mathrm{O} \\
\end{array}$ & [26] & $\begin{array}{l}\text { Active power } \\
\text { loss }\end{array}$ & $\begin{array}{l}\text { IEEE 14-bus and } \\
\text { IEEE30-bus }\end{array}$ \\
\hline ICA-PSO & [27] & $\begin{array}{l}\text { Active power } \\
\text { loss and voltage } \\
\text { deviation }\end{array}$ & $\begin{array}{l}\text { IEEE57-bus and } \\
\text { IEEE118-bus }\end{array}$ \\
\hline HABC & [28] & $\begin{array}{l}\text { Active power } \\
\text { loss }\end{array}$ & $\begin{array}{l}\text { IEEE 6-bus, } \\
\text { IEEE14-bus, and } \\
\text { IEEE 30-bus }\end{array}$ \\
\hline $\begin{array}{c}\text { 2ArchMG } \\
\text { WO }\end{array}$ & [29] & $\begin{array}{l}\text { Active power } \\
\text { loss and voltage } \\
\text { profile }\end{array}$ & $\begin{array}{l}\text { IEEE 30-bus, } \\
\text { IEEE 57-bus and } \\
\text { IEEE 118-bus }\end{array}$ \\
\hline ABO-TRL & [30] & $\begin{array}{l}\text { Active power } \\
\text { loss and voltage } \\
\text { deviation }\end{array}$ & $\begin{array}{l}\text { IEEE118-bus } \\
\text { and IEEE 300- } \\
\text { bus }\end{array}$ \\
\hline WOA & [31] & $\begin{array}{l}\text { Active power } \\
\text { loss }\end{array}$ & $\begin{array}{l}\text { IEEE 14-bus, } \\
\text { IEEE 30-bus, } \\
\text { Algerian electric } \\
\text { 114-bus }\end{array}$ \\
\hline ABC-FF & [32] & $\begin{array}{l}\text { Active power } \\
\text { loss and voltage } \\
\text { stability }\end{array}$ & $\begin{array}{l}\text { IEEE } 14 \text { and } \\
\text { IEEE } 39 \text { bus }\end{array}$ \\
\hline DEEPSO & [33] & $\begin{array}{l}\text { Active power } \\
\text { loss }\end{array}$ & $\begin{array}{l}\text { IEEE 30-bus, } \\
\text { IEEE 57-bus and } \\
\text { IEEE 118-bus }\end{array}$ \\
\hline HSA & [34] & $\begin{array}{l}\text { Active power } \\
\text { loss }\end{array}$ & $\begin{array}{l}\text { IEEE 14-bus and } \\
\text { IEEE 57-bus }\end{array}$ \\
\hline
\end{tabular}

Recently, Sine Cosine Algorithm (SCA) has been proposed by Seyedali et al in 2016. SCA has a variety of benefits and is unique from other algorithms such as GSA etc. Those are shown in detail [35].Moreover, in [35], SCA was tested on 19 different mathematical benchmark functions and aircraft design problem related with other algorithms such as the Flower Pollination Algorithm (FPA), Gravitational Search Algorithm (GSA), Firefly Algorithm (FA) and Bat Algorithm (BA).The results achieved by SCA in most cases offer better results comparable with other algorithms. The SCA's most important feature is that numerous initial random candidate solutions are generated to oscillate outward or toward the optimal solution using a mathematical equation of sine and cosine functions. This algorithm also combines several random and adaptive variables to highlight exploration and use of the search space in various signs of optimization. For all these reasons,
SCA is selected to solve the ORPD problem in this paper. The ORPD is determined by the constraints of equality and inequality as a non-linear optimization problem. To assess the dependability of the proposed algorithm, IEEE 14/57bus and 118-bus test systems are tested with various objective functions reflecting active power losses and enhancement of the voltage profile, and results obtained from SCA were compared with those reported in the past.

\section{PROBLEM STATEMENT}

\section{Minimization of active power losses}

The main objective of multi-objective optimization is to reduce the active power loss in the transmission network, as described below [8-34]:

$$
F_{1}=\sum_{k=1}^{N T} P_{l o s s, \mathrm{k}}=\sum_{k=1}^{N T} G_{k}\left(V_{i}^{2}+V_{j}^{2}\right)-2 V_{i} V_{j} \cos \left(\delta_{i}-\delta_{j}\right)
$$

Where $N T$ is the number of transmission lines, $G_{k}$ is the conductance of the $k^{\text {th }}$ line, $V_{i}$ and $V_{j}$ are the voltage magnitude of the $i^{\text {th }}$ and $j^{\text {th }}$ buses, and $\delta_{i}$ and $\delta_{j}$ are the voltage phase angles of $i^{\text {th }}$ and $j^{\text {th }}$ buses.

\section{Dependent $(x)$ and control variables $(u)$}

For the Eq. (1), $\mathrm{x}$ and $\mathrm{u}$ are vectors of dependent and control variables, respectively. The vector of dependent variables $\boldsymbol{x}$ can be expressed as

$$
x^{T}=\left[P_{G 1}, V_{L 1} \ldots V_{\mathrm{LNPQ}}, \mathrm{Q}_{G 1} \ldots \mathrm{Q}_{\mathrm{GNPV}}\right]
$$

Where, $\mathrm{P}_{G l}$ denotes the real power of slack bus, $\mathrm{V}_{L}$ is the voltage at the PQ buses, $\mathrm{Q}_{G}$ is the reactive power of generator buses, $N P V$ defines the number of voltage controlled $(P V)$ buses, $N P Q$ is the number of $P Q$ buses.

The vector of control variables $u$ can be represented as

$$
u^{T}=\left[V_{G 1} \ldots V_{\mathrm{GNPV}}, \mathrm{Q}_{\mathrm{C} 1} \ldots \mathrm{Q}_{\mathrm{CNC}}, T_{1} \ldots T_{N T}\right]
$$

Where, $N T$ and $N C$ are the number of tap changing transformers and shunt VAR compensators, respectively. $\mathrm{V}_{\mathrm{G}}$ defines the terminal voltages at the PV bus, $T$ is the tap ratio of the tap changing transformers and $Q_{C}$ is the output of shunt VAR compensators.

\section{Improvement of voltage profile}

Another aim of this problem is to improve the voltage profile which is formulated mathematically as follows [13,17,19-21,24,29],

$$
F_{2}=\sum_{i=1}^{N P Q}\left|V_{\mathrm{i}, \mathrm{spec}}-V_{i}\right|
$$

Where $N P Q$ is the number of load buses in the power system and $\mathrm{V} i$ is the reference value of the voltage magnitude of the $\mathrm{i}^{\text {th }}$ bus which is equal to $1.0(\mathrm{pu})$

By combining the Eq. (1) and Eq. (2) leads to the main objective function as follows:

$$
F_{o b j}=F_{1}+F_{2}=\left(\sum_{k=1}^{N T} P_{l o s s, \mathrm{k}}\right)+\left(\sum_{i=1}^{N P Q}\left|V_{\mathrm{i}, \mathrm{spec}}-V_{i}\right|\right)
$$

\section{Constraints}




\section{Equality constraints}

These constraints, which are load flow equations, are described as follows

$$
\begin{gathered}
P_{G i}-P_{D i}-\sum_{j \in N B} V_{i} V_{j}\left(G_{i j} \cos \delta_{i j}+B_{i j} \sin \delta_{i j}\right)=0(6) \\
Q_{G i}-Q_{D i}-\sum_{j \in N B} V_{i} V_{j}\left(G_{i j} \sin \delta_{i j}+B_{i j} \cos \delta_{i j}\right)=0(7)
\end{gathered}
$$

Where $N B$ is the number of buses, $P_{G i}$ and $Q_{G i}$ are generated real and reactive power, $P_{D i}$ and $Q_{D i}$ are load real and reactive power, $G_{i j}$ is the transfer conductance and $B_{i j}$ is the transfer susceptance between $i^{\text {th }}$ bus and $j^{\text {th }}$ bus, respectively.

\section{Equality constraints}

\section{Generator constraints}

Generator voltages, reactive outputs ought to be restricted by their lower and upper limits as follows

$Q_{G, i}^{\min } \leq Q_{G, i} \leq Q_{G, i}^{\max }$

$V_{G, i}^{\min } \leq V_{G, i} \leq V_{G, i}^{\max }$

\section{Transformer constraints}

Transformer tap setting are bounded as follows: $T_{i}^{\min } \leq T_{i} \leq T_{i}^{\max }$ $\mathrm{i} \in$ No.of transformers

\section{Shunt VAr compensator constraints}

Shunt VAR compensators should be constrained as follows by their lower and upper limits

$Q_{\mathrm{C}, i}^{\min } \leq Q_{\mathrm{C}, i} \leq Q_{\mathrm{C}, i}^{\max }$

\section{Security constraints}

These include the voltage constraints at load buses and the loading of the transmission line as follows:

$V_{\mathrm{L}, i}^{\min } \leq V_{\mathrm{L}, i} \leq V_{\mathrm{L}, i}^{\max }$

$$
S_{\mathrm{L}, i} \leq S_{\mathrm{L}, i}^{\max }
$$

Where $S_{L, i}$ is the apparent power flow in the transmission line $i, S_{\mathrm{L}, i}^{\max }$ is the maximum limits of apparent flow in the transmission line. $N T$ is the number of transmission lines in the system.

Dependent variables are considered as constraints to the objective function using penalty values. Therefore, Eq. (1) and Eq. (2) are combined as:

$F_{n e w}=F_{o b j}+\lambda_{V} \sum_{i=1}^{N P Q}\left(V_{i}-V_{i}^{\lim }\right)^{2}+\lambda_{Q} \sum_{i=1}^{N G}\left(Q_{G, i}-Q_{G, i}^{\lim }\right)^{2}$

$x^{\lim }$ is the limit value of the dependent variable $x=\left(V_{i}\right.$ and $Q_{G}$ ) and given as:

$$
x^{\lim }=x^{\max } \text { if } x>x^{\max } \text {, and } x^{\lim }=x^{\min } \text { if } x<x^{\min }
$$

Where $\lambda_{V}$ and $\lambda_{Q}$ are the weighting factors to enhance the objective function.

\section{SINE COSINE OPTIMIZATION ALGORITHM}

Regardless of the variances in the field of optimization between optimization algorithms, the green is the divergence of the optimization system into two phases: exploration versus exploitation. In the previous step, an optimization algorithm blends unexpectedly random solutions in the set of solutions with a high rate of randomness in order to find the shining sections of the search space. However, there are incremental changes in random solutions in the development phase, and random differences are significantly lower than in the exploration stage.

In this SCA [35], the following position updating equations is proposed for both phases:

$$
\begin{aligned}
& X_{i}^{t+1}=X_{i}^{t}+r_{1} \times \sin \left(r_{2}\right) \times\left\|r_{3} P_{i}^{t}-X_{i}^{t}\right\| \\
& X_{i}^{t+1}=X_{i}^{t}+r_{1} \times \cos \left(r_{2}\right) \times\left\|r_{3} P_{i}^{t}-X_{i}^{t}\right\|
\end{aligned}
$$

Where $X_{i}^{t}$ is the position of the current solution in $i^{\text {-th }}$ dimension at $t^{\text {th }}$ iteration, $r_{1} / r_{2} / r_{3}$ are random numbers, $P_{i}$ is position of the destination point in $i^{\text {th }}$ dimension, and $\|$ indicates the absolute value.

By combining the Eq. (15) and Eq. (16), it will be used as,

$$
X_{i}^{t+1}=\left\{\begin{array}{l}
X_{i}^{t}+r_{1} \times \sin \left(r_{2}\right) \times\left\|r_{3} P_{i}^{t}-X_{i}^{t}\right\| r_{4}<0.5 \\
X_{i}^{t}+r_{1} \times \cos \left(r_{2}\right) \times\left\|r_{3} P_{i}^{t}-X_{i}^{t}\right\| r_{4} \geq 0.5
\end{array}\right.
$$

Where $r_{4}$ is a random number in [0,1].From the Eq. (17), there are four main parameters in the SCA: $r_{1}, r_{2}, r_{3}$ and $r_{4}$.

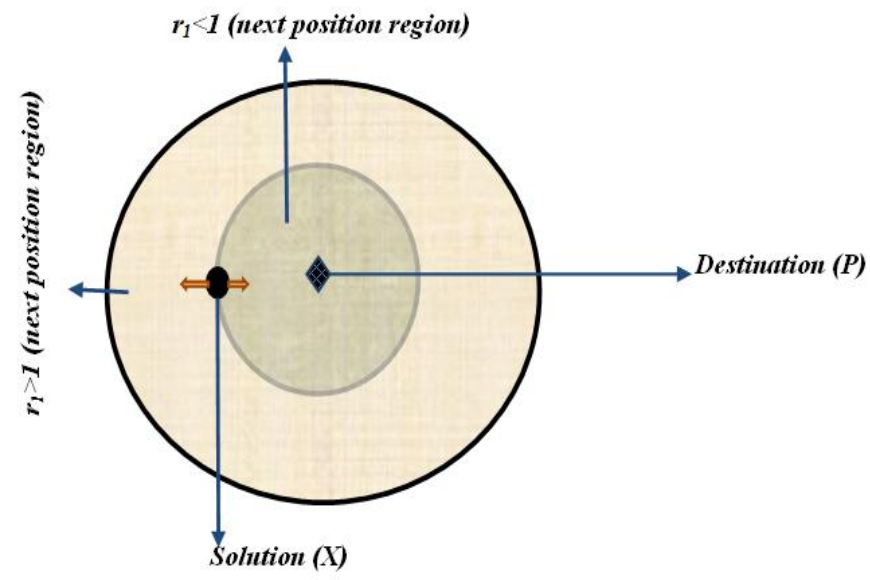

Fig. 1 Properties of Sine and Cosine on the next position region

Sine and Cosine's property on Esq. (15) and (16) are shown in Fig. 1. This act illustrates how the proposed equations describe a space in the search space between two solutions. It should be noted that, although a twodimensional case is illustrated in Fig. 1, this formula can be applied to higher dimensions. 


\section{Reactive Power Control using Sine Cosine Algorithm for Active Power Loss Minimization with Voltage Profile Enhancement}

The solutions should also be able to search outside the space between their corresponding destinations in order to investigate the search space. This can be done by modifying the functions of sin and cosine. Fig. 2 shows a conceptual model of the effects of sine and cosine functionalities with the scope in $[-2,2]$.

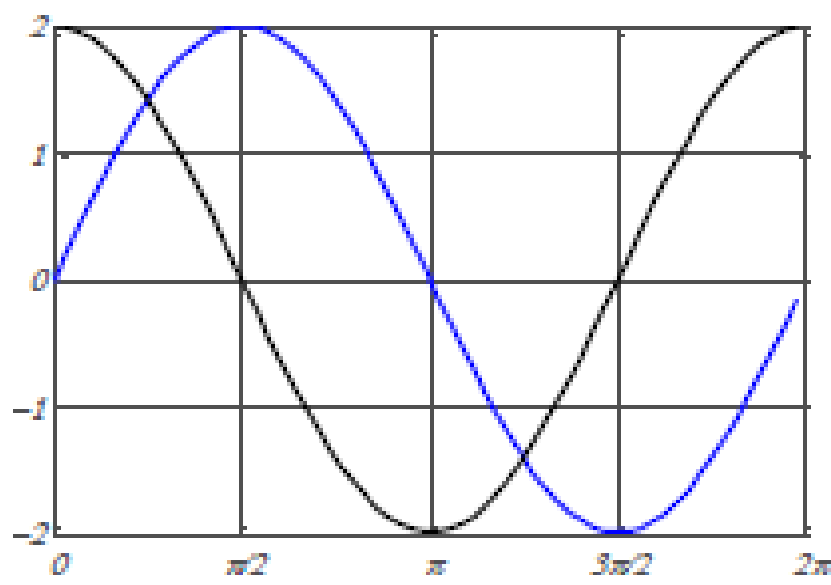

Fig. 2 Sine and cosine with range of [-2,2]

The following equation is used to update the value of $r_{l}$ in Eqs. (15) to (17),

$r_{1}=a-t \frac{a}{T}$

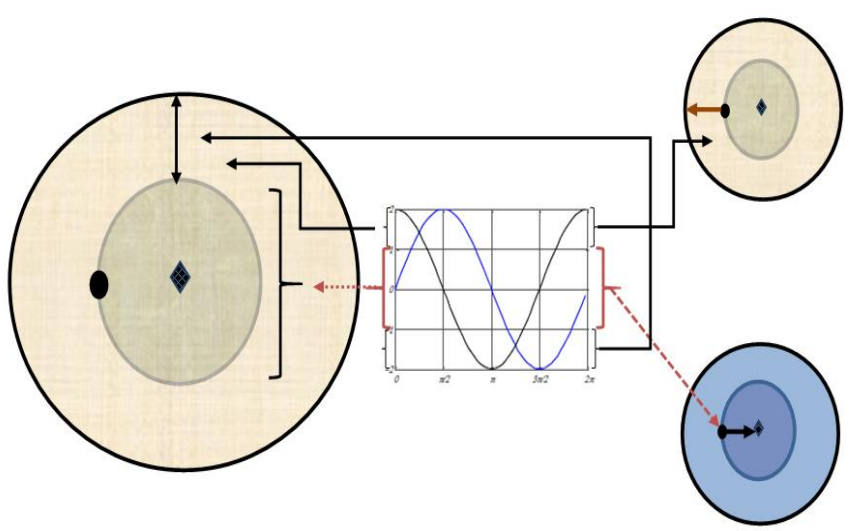

Fig. 3 Sine and cosine function with the range in [-2,2] allow a solution to go around the destination

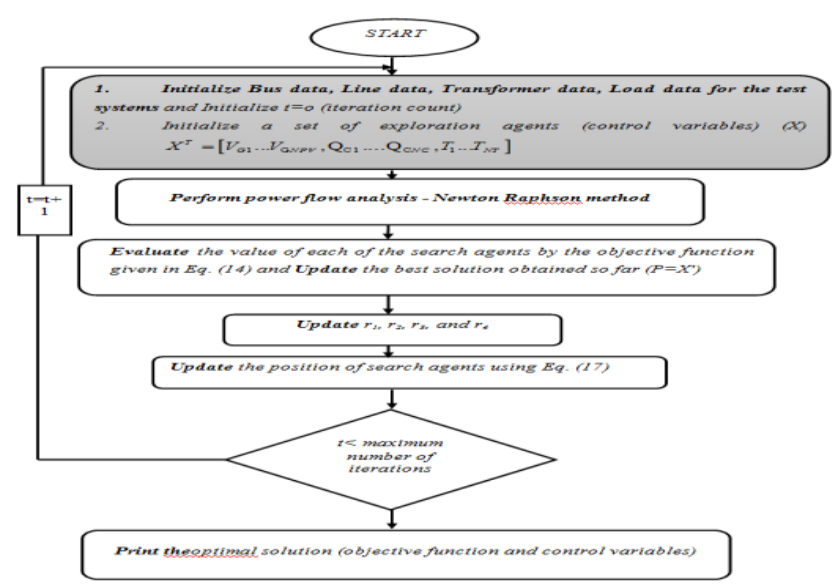

Fig. 4 Flow chart for the SCA Algorithm - ORPD problem
Where $t$ is the current iteration, $T$ is the maximum number of iterations, and $a$ is a constant.

It can be inferred from Fig. (3) the search space is explored by the SCA algorithm when the sine and cosine function ranges are in $(1,2)$ and $[-2,-1)$. All the same, when the ranges are in $[-1,1]$ interval, this algorithm exploits the search space.

\section{Implementation of Sine Cosine Optimization Algorithm for ORPD with FACTS devices}

Step 1: Initialization the set of search agents (control variables) $(\mathrm{X})$.

$$
X^{T}=\left[V_{G 1} \ldots V_{\mathrm{G} N P V}, \mathrm{Q}_{\mathrm{C} 1} \ldots \mathrm{Q}_{\mathrm{CNC}}, T_{1} \ldots T_{N T}\right]
$$

Step 2: Perform Newton Raphson load flow analysis, and ascertain the solution using Eq. (14) for the initialized set of search agents from step 1 .

Step 3: Save the best solutions obtained so far, assigns it as the final tip $\left(\mathrm{P}=\mathrm{X}^{\prime}\right)$, and update the other solutions with respect to it.

Measure 4: Meanwhile, the sine and cosine function ranges $(r 1, r 2, r 3$, and $r 4)$ are updated to emphasize search space development as the iteration counter increases.

Pace 5: Check the termination criteria (SCA algorithm ends the optimization process in this study when the iteration counter is higher than the default upper limit number of iterations).If its satisfied, publish the best solution (objective function and control variables) else Update the status of search agents using Eq. (17) and GOTO step 2.

\section{TEST SYSTEMS}

Sine, cosine algorithm is given in this paper to standard IEEE 14, IEEE 57 and IEEE 118 test systems for solving the traditional ORPD problem [35,36]. 25 Test runs were also performed for each of the processes and for comparison the best results of each process were presented. In each case, the maximum number of iterations was taken at 1000 . One line diagram of all the test systems was given in Fig. (9), (10) and Fig. (11) with its description is depicted in Table2.All the necessary details about the test systems were taken from MATPOWER tool box [37].

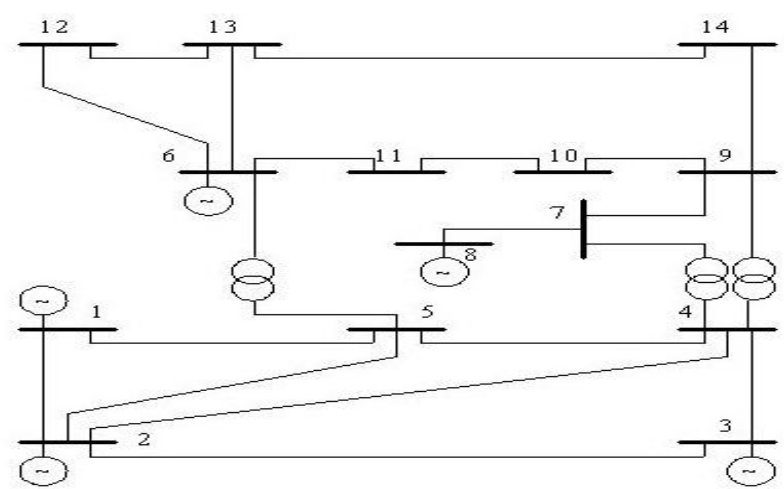

Fig. 5 Single line diagram - IEEE-14 bus system 


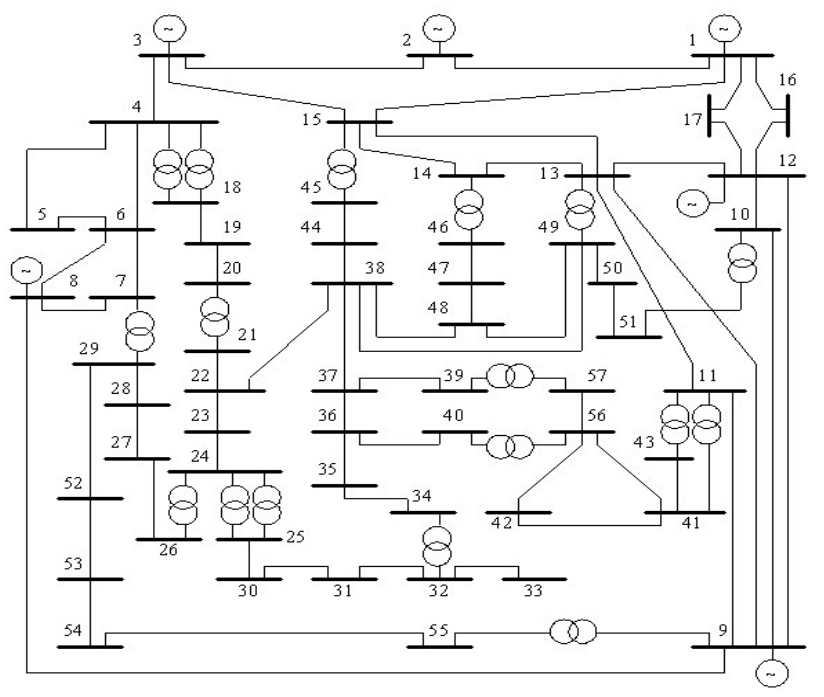

Fig. 6 Single line diagram - IEEE-57 bus system

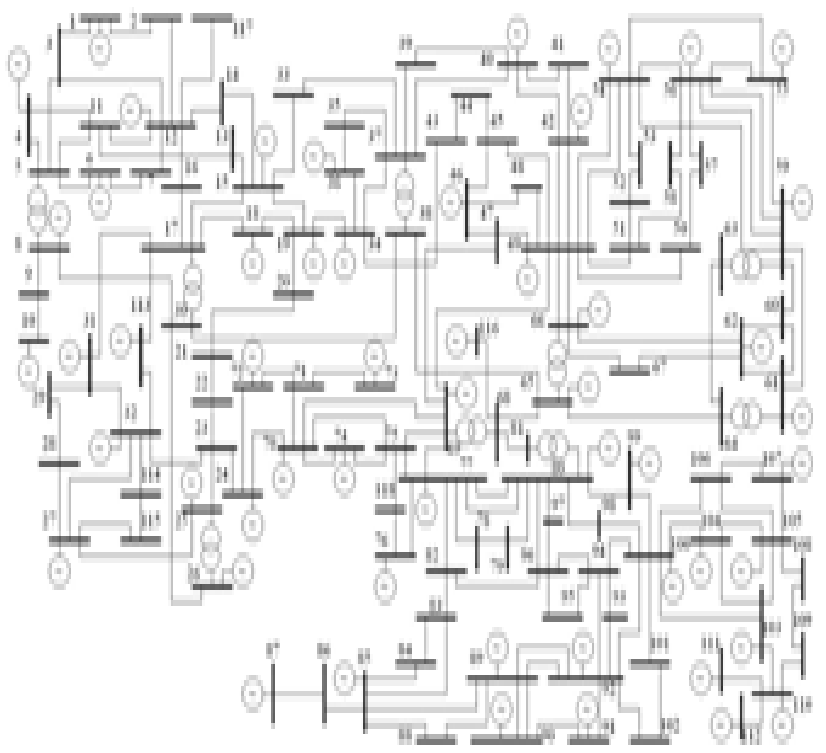

Fig. 7 Single line diagram - IEEE-118 bus system

Table. 2 Summary of test systems - Base case

\begin{tabular}{|l|l|l|l|}
\hline Description & $\begin{array}{l}\text { IEEE } \\
\text { 14-bus }\end{array}$ & $\begin{array}{l}\text { IEEE } \\
\text { 57-bus }\end{array}$ & $\begin{array}{l}\text { IEEE } \\
\text { 118-bus }\end{array}$ \\
\hline Buses & 14 & 57 & 118 \\
\hline Generators & 5 & 7 & 54 \\
\hline Transformers & 3 & 15 & 9 \\
\hline Shunts & 2 & 3 & 14 \\
\hline Branches & 20 & 80 & 186 \\
\hline Control variables & 10 & 25 & 77 \\
\hline Base case $P_{\text {Load }}(\mathrm{MW})$ & 259.00 & 1250.80 & 4242 \\
\hline $\begin{array}{l}\text { Base case QLoad } \\
\text { (MVAr) }\end{array}$ & 73.50 & 336.40 & 1438 \\
\hline Base case $\mathrm{P}_{\text {Loss }}(\mathrm{MW})$ & 13.49 & 28.462 & 132.283 \\
\hline
\end{tabular}

\section{RESULTS AND DISCUSSION}

\section{Test system 1: Standard IEEE-14 bus system}

The standard IEEE 14-bus system consists of 20 transmission lines for 4-7, 4-9 and 5-6 transformer branches, five generators at 1, 2, 3, 6 and 8 and 15 branches under load tap setting. Busses 9 and 14 consider the reactive power sources. Details of the system, variable limits, and initial control variables values were presented in $[26,36]$. Initially, $\mathrm{P}_{\text {Load }}$ is $259 \mathrm{MW}$ and $\mathrm{Q}_{\text {Load }}$ is $73.50 \mathrm{MVAr}$ before optimization. The upper and lower limits of the test system's control variable limits are given separately in Table 6-8.

Table. 3 Minimum and Maximum limits of control variables for IEEE 14 bus system

\begin{tabular}{|c|c|c|c|c|c|}
\hline \multicolumn{2}{|c|}{ Generator } & \multicolumn{2}{|c|}{ Transformer } & \multirow{2}{*}{$\frac{\text { Reactive }}{Q_{C}^{\min }}$} & \multirow{2}{*}{$\frac{\text { power }}{Q_{C}^{\max }}$} \\
\hline$V_{G}^{\text {min }}$ & $V_{G}^{\max }$ & $T_{i}^{\min }$ & $T_{i}^{\max }$ & & \\
\hline 0.95 & 1.1 & 0.9 & 1.1 & -0.3 & 0.3 \\
\hline
\end{tabular}

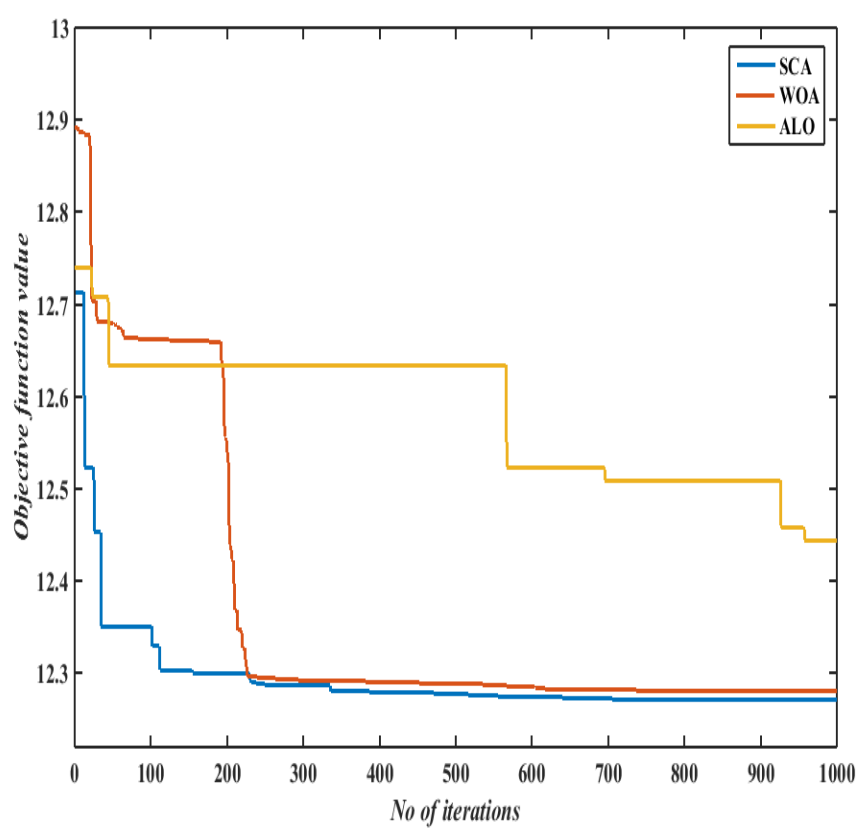

Fig. 8 Convergence curve of IEEE-14 bus system

The proposed approach is used to minimize active power losses with the objective function of improving the voltage profile. Table 1 shows the optimal values of the control variables obtained from the proposed SCA method. The minimum active power loss obtained from the proposed SCA approach is $12.2715 \mathrm{MW}$ from the 13.49 MW active power loss in the base case. Fig. 3 Represents the SCA convergence characteristic for the objective function proposed. It proves that the SCA finds the better convergence compared with WOA and ALO. Table 6 shows the effects obtained from the proposed SCA technique compared to the other methods in the literature with each algorithm's computational time. It can be seen that both the power loss and the computing time of the SCA are less than the other algorithms mentioned in the literature.

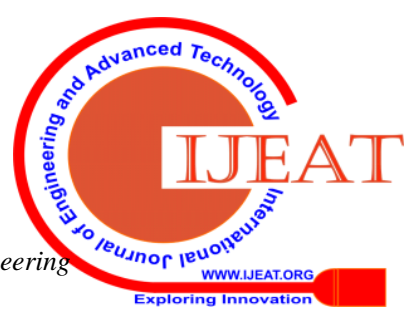


Reactive Power Control using Sine Cosine Algorithm for Active Power Loss Minimization with Voltage Profile Enhancement

Table. 4 Best control variables settings and active power loss for IEEE 14 bus system

\begin{tabular}{|c|c|c|c|c|c|c|}
\hline \multirow{2}{*}{$\begin{array}{l}\begin{array}{l}\text { Control } \\
\text { variables }\end{array} \\
\text { Optimization } \\
\text { method }\end{array}$} & \multicolumn{6}{|l|}{$O R P D$} \\
\hline & $\begin{array}{l}S C A \\
\text { (proposed) }\end{array}$ & $\begin{array}{l}\text { WOA } \\
\text { (proposed) }\end{array}$ & $\begin{array}{l}\text { ALO } \\
\text { (proposed) }\end{array}$ & HSA[34] & IHSA[34] & $\begin{array}{l}\text { MGBTLBO } \\
{[26]}\end{array}$ \\
\hline \multicolumn{7}{|c|}{ Generator voltage } \\
\hline$V_{l,}(p u)$ & 1.0931 & 0.9760 & 1.0515 & 1.0899 & 1.0932 & 1.1000 \\
\hline$V_{2},(p u)$ & 1.0116 & 1.0232 & 0.9930 & 1.0659 & 1.0650 & 1.0791 \\
\hline$V_{3},(p u)$ & 1.1000 & 1.0235 & 1.0177 & 1.0448 & 1.0461 & 1.0485 \\
\hline$V_{6},(p u)$ & 1.0865 & 1.1000 & 1.1000 & 0.9887 & 1.0703 & 1.0552 \\
\hline$V_{8},(p u)$ & 1.0580 & 1.0866 & 1.0753 & 1.0092 & 1.0362 & 1.0326 \\
\hline \multicolumn{7}{|c|}{ Transformer tap ratio } \\
\hline $\mathrm{T}_{4-7}$ & 1.0931 & 1.0589 & 1.0575 & 1.0458 & 1.0159 & 1.0100 \\
\hline $\mathrm{T}_{4-9}$ & 1.0972 & 1.1000 & 1.0472 & 0.9544 & 1.0200 & 1.0100 \\
\hline $\mathrm{T}_{5-6}$ & 1.0594 & 1.0354 & 0.9763 & 1.0866 & 0.9926 & 1.0300 \\
\hline \multicolumn{7}{|c|}{ Capacitor banks } \\
\hline$Q \mathrm{C}_{-9}(\mathrm{MVAr})$ & 27.3476 & 25.5553 & 29.6613 & 12.7368 & 16.0675 & 30.0000 \\
\hline$Q \mathrm{c}_{-14}(\mathrm{MVAr})$ & 29.2124 & 25.9727 & 25.3325 & 10.4165 & 18.3021 & 7.0000 \\
\hline$P_{\text {Loss }}(M W)$ & 12.2715 & 12.2804 & 12.4443 & 12.8060 & 12.7890 & 12.3106 \\
\hline
\end{tabular}

Table. 5 Best solutions of all algorithms for IEEE 14 bus system

\begin{tabular}{|l|l|l|l|l|l|}
\hline Algorithms & Best $(\mathbf{p u})$ & Worst $(\mathbf{p u})$ & Mean $(\mathbf{p u})$ & Std. deviation & \% $\boldsymbol{P}_{\text {save }}$ \\
\hline DE [10] & 0.1324 & 0.1328 & 0.1325 & $1.61 \times 10^{-4}$ & 1.86 \\
\hline PSO [34] & 0.1325 & 0.1340 & 0.1335 & $0.64 \times 10^{-3}$ & 1.75 \\
\hline ACOR[34] & 0.1312 & 0.1357 & 0.1339 & $7.1854 \times 10^{-2}$ & 2.72 \\
\hline DE/best/2/bin[34] & 0.1299 & 0.1301 & 0.1309 & $6.5036 \times 10^{-4}$ & 3.7 \\
\hline ABC[34] & 0.1293 & 0.1312 & 0.1296 & $9.422 \times 10^{-4}$ & 4.13 \\
\hline LCA[34] & 0.1299 & 0.1316 & 0.1305 & $5.5283 \times 10^{-3}$ & 3.71 \\
\hline CSS[34] & 0.1297 & 0.1330 & 0.1312 & $4.206 \times 10^{-2}$ & 3.82 \\
\hline BRCFF[34] & 0.1293 & 0.1298 & 0.1293 & $8.8191 \times 10^{-5}$ & 4.18 \\
\hline BB-BC[34] & 0.1300 & 0.1323 & 0.1311 & $4.7604 \times 10^{-3}$ & 3.6 \\
\hline PBIL[34] & 0.1300 & 0.1319 & 0.1309 & $9.7075 \times 10^{-4}$ & 3.63 \\
\hline TLA[34] & 0.1292 & 0.1295 & 0.1293 & $9.0283 \times 10^{-5}$ & 4.2 \\
\hline MTLA [34] & 0.1291 & 0.1292 & 0.1292 & $7.6832 \times 10^{-5}$ & 4.3 \\
\hline DDE [34] & 0.1293 & 0.1293 & 0.1293 & $5.0065 \times 10^{-5}$ & 4.16 \\
\hline MTLA-DDE[34] & 0.1290 & 0.1290 & 0.1290 & $6.486 \times 10^{-6}$ & 4.39 \\
\hline TLBO [26] & 0.1299 & 0.1299 & 0.1299 & $9.28 \times 10^{-5}$ & 3.72 \\
\hline BBPSO [26] & 0.1299 & 0.1300 & 0.1299 & $9.45 \times 10^{-5}$ & 3.69 \\
\hline BBDE [26] & 0.1300 & 0.1311 & 0.1300 & $8.62 \times 10^{-5}$ & 3.64 \\
\hline GBTLBO [26] & 0.1242 & 0.1242 & 0.1242 & $0.75 \times 10^{-5}$ & 7.97 \\
\hline MGBTLBO [26] & 0.1231 & 0.1236 & 0.1232 & $0.42 \times 10^{-5}$ & 8.74 \\
\hline HAS [34] & 0.1281 & 0.1283 & 0.1281 & $5.346 \times 10^{-6}$ & 5.07 \\
\hline IHSA [34] & 0.1279 & 0.1288 & 0.1281 & $6.974 \times 10^{-6}$ & 5.20 \\
\hline ALO (proposed) & 0.1244 & 0.1255 & 0.1261 & $5.98 \times 10^{-6}$ & 7.78 \\
\hline WOA (proposed) & 0.1228 & 0.1288 & 0.1289 & $6.89 \times 10^{-6}$ & 8.96 \\
\hline SCA (proposed) & $\mathbf{0 . 1 2 2 7}$ & $\mathbf{0 . 1 2 5 3}$ & $\mathbf{0 . 1 2 2 8}$ & $\mathbf{5 . 7 3 \times 1 0 ^ { - 6 }}$ & $\mathbf{9 . 0 3}$ \\
\hline
\end{tabular}

Test system 2: Standard IEEE-57 bus system

The standard IEEE 57-bus system consists of 80 transmission lines, 7 generators at $1,2,3,6,8,9,12$ and branches under the transformer branches of the load tap setting. Busses 18, 25 and 53 are known as reactive power sources.In $[12,17,19,23,24]$ the system line data, bus information, variable limits and initial control variables values were provided. This case system's search space has 25 dimensions including 7 voltages of generators, 15 taps of transformers and 3 reactive sources. The upper and lower limits of the test system's reactive power generation and control variable limits are given respectively in Table 6-8. The total load of the system is $1250.8 \mathrm{MW}$ and 336.4 MVAr. The active power loss of the initial system is 28.462 MW. 
Table. 6 Minimum and Maximum limits of control variables for IEEE-57 bus system

\begin{tabular}{|c|c|c|c|c|c|c|c|c|c|c|c|c|c|c|}
\hline \multicolumn{15}{|c|}{ Reactive power sources (pu) } \\
\hline \multicolumn{8}{|c|}{$Q_{C}^{\min }$} & \multicolumn{7}{|c|}{$Q_{C}^{\max }$} \\
\hline Bus No & 1 & 2 & 3 & 6 & 8 & 9 & 12 & 1 & 2 & 3 & 6 & 8 & 9 & 12 \\
\hline Values & -1.4 & -0.17 & -0.1 & -0.08 & -1.4 & -0.03 & -1.5 & 2.0 & 0.5 & 0.6 & 0.25 & 2.0 & 0.09 & 1.55 \\
\hline \multicolumn{8}{|c|}{ Generator voltages $(\mathrm{pu})$} & \multicolumn{7}{|c|}{ Transformer taps } \\
\hline \multicolumn{3}{|c|}{$V_{G}^{\min }$} & \multicolumn{5}{|c|}{$V_{G}^{\max }$} & \multicolumn{2}{|c|}{$T_{i}^{\min }$} & \multicolumn{5}{|c|}{$T_{i}^{\max }$} \\
\hline \multicolumn{3}{|l|}{0.95} & \multicolumn{5}{|l|}{1.1} & \multicolumn{2}{|c|}{0.9} & \multicolumn{5}{|c|}{1.1} \\
\hline
\end{tabular}

Table. 7 Best control variables settings and active power loss for IEEE 57 bus system

\begin{tabular}{|c|c|c|c|c|c|c|c|c|c|c|c|}
\hline \multirow[b]{2}{*}{ Control variables } & \multicolumn{11}{|c|}{$O R P D$} \\
\hline & $\begin{array}{c}S C A \\
\text { (proposed) }\end{array}$ & $\begin{array}{c}\text { WOA } \\
\text { (proposed) }\end{array}$ & $\begin{array}{c}A L O \\
\text { (proposed) }\end{array}$ & IHSA [34] & HSA[34] & GSA [19] & $\begin{array}{r}B B O \\
{[17]}\end{array}$ & SOA [12] & ICA[23] & IWO [23] & $\begin{array}{c}\text { MICA- } \\
\text { IWO [23] }\end{array}$ \\
\hline $\mathrm{V}_{l}(\mathrm{pu})$ & 1.1000 & 1.1000 & 1.1000 & 1.0954 & 1.0938 & 1.0600 & 1.0600 & 1.0600 & 1.0600 & 1.0600 & 1.0600 \\
\hline $\mathrm{V}_{2}(\mathrm{pu})$ & 1.1000 & 1.1000 & 1.0986 & 1.0814 & 1.0780 & 1.0600 & 1.0504 & 1.0580 & 1.0575 & 1.0591 & 1.0584 \\
\hline $\mathrm{V}_{3}(\mathrm{pu})$ & 1.0768 & 1.1000 & 1.0865 & 1.0688 & 1.0628 & 1.0600 & 1.0440 & 1.0437 & 1.0423 & 1.0472 & 1.0457 \\
\hline $\mathrm{V}_{6}(\mathrm{pu})$ & 1.0558 & 1.1000 & 1.0789 & 1.0743 & 1.0724 & 1.0081 & 1.0376 & 1.0352 & 1.0350 & 1.0382 & 1.0397 \\
\hline $\mathrm{V}_{8}(\mathrm{pu})$ & 1.0566 & 1.1000 & 1.1000 & 1.0951 & 1.0980 & 1.0550 & 1.0550 & 1.0548 & 1.0509 & 1.0593 & 1.0600 \\
\hline $\mathrm{V}_{9}(\mathrm{pu})$ & 1.0795 & 1.1000 & 1.0865 & 1.0704 & 1.0699 & 1.0098 & 1.0229 & 1.0369 & 1.0192 & 1.0273 & 1.0274 \\
\hline $\mathrm{V}_{12},(\mathrm{pu})$ & 1.1000 & 1.1000 & 1.0826 & 1.0699 & 1.0649 & 1.0186 & 1.0323 & 1.0336 & 1.0287 & 1.0374 & 1.0350 \\
\hline $\mathrm{T}_{4-18}$ & 0.9037 & 0.9000 & 1.0983 & 1.0699 & 1.0737 & 1.1000 & 0.9669 & 1.0000 & 0.9000 & 1.0500 & 1.0100 \\
\hline $\mathrm{T}_{4-18}$ & 1.0765 & 1.1000 & 1.0996 & 1.0564 & 1.0509 & 1.0826 & 0.9902 & 0.9600 & 1.0100 & 1.0000 & 0.9500 \\
\hline $\mathrm{T}_{21-20}$ & 1.0284 & 1.1000 & 1.0822 & 1.0440 & 1.0487 & 0.9220 & 1.0120 & 1.0100 & 1.0000 & 1.0700 & 1.0200 \\
\hline $\mathrm{T}_{24-26}$ & 0.9033 & 0.9000 & 1.0274 & 1.0642 & 1.0683 & 1.0167 & 1.0087 & 1.0100 & 1.0100 & 1.0200 & 1.0100 \\
\hline $\mathrm{T}_{7-29}$ & 0.9998 & 0.9000 & 1.0593 & 1.0225 & 1.0190 & 0.9963 & 0.9707 & 0.9700 & 0.9700 & 0.9700 & 0.9600 \\
\hline $\mathrm{T}_{34-32}$ & 0.9000 & 1.1000 & 1.0299 & 1.0596 & 1.0605 & 1.1000 & 0.9687 & 0.9700 & 0.9800 & 0.9900 & 0.9800 \\
\hline $\mathrm{T}_{11-41}$ & 0.9637 & 0.9658 & 1.0757 & 0.9695 & 0.9649 & 1.0746 & 0.9008 & 0.9000 & 0.9000 & 0.9000 & 0.9000 \\
\hline $\mathrm{T}_{15-45}$ & 1.0515 & 0.9868 & 0.9911 & 0.9630 & 0.9573 & 0.9543 & 0.9660 & 0.9700 & 0.9600 & 0.9600 & 0.9500 \\
\hline $\mathrm{T}_{14-46}$ & 1.0075 & 0.9075 & 1.0160 & 0.9399 & 0.9447 & 0.9377 & 0.9508 & 0.9500 & 0.9400 & 0.9500 & 0.9400 \\
\hline $\mathrm{T}_{10-51}$ & 1.0257 & 0.9868 & 1.0395 & 0.9768 & 0.9783 & 1.0168 & 0.9641 & 0.9600 & 0.9500 & 0.9800 & 0.9500 \\
\hline $\mathrm{T}_{13-49}$ & 1.0141 & 0.9000 & 0.9920 & 0.9401 & 0.9464 & 1.0526 & 0.9246 & 0.9200 & 0.9200 & 0.9300 & 0.9100 \\
\hline $\mathrm{T}_{11-43}$ & 1.0432 & 0.9435 & 1.0431 & 1.0986 & 1.0896 & 1.1000 & 0.9502 & 0.9600 & 0.9500 & 0.9900 & 0.9500 \\
\hline $\mathrm{T}_{40-56}$ & 0.9143 & 1.0554 & 0.9963 & 0.9517 & 0.9524 & 0.9800 & 0.9967 & 1.0000 & 1.0000 & 1.0100 & 1.0000 \\
\hline $\mathrm{T}_{39-57}$ & 0.9753 & 1.0320 & 1.0450 & 1.0570 & 1.0557 & 1.0247 & 0.9629 & 0.9600 & 0.9600 & 1.0400 & 0.9700 \\
\hline $\mathrm{T}_{9-55}$ & 0.9699 & 0.9410 & 1.0491 & 1.0001 & 1.0024 & 1.0373 & 0.9600 & 0.9700 & 0.9600 & 0.9600 & 0.9600 \\
\hline $\mathrm{Q}_{C-18}(\mathrm{MVAr})$ & 23.4334 & 26.5356 & 23.5968 & 13.3960 & 15.5030 & 7.8254 & 9.7820 & 9.9840 & 4.1000 & 4.4200 & 10.0000 \\
\hline $\mathrm{Q}_{C-25}(\mathrm{MVAr})$ & 13.2658 & 16.4014 & 18.6583 & 8.5066 & 6.8815 & 0.5869 & 5.8991 & 5.9040 & 5.9000 & 4.3300 & 5.9000 \\
\hline $\mathrm{Q}_{C-53}(\mathrm{MVAr})$ & 28.1163 & 15.4301 & 17.4103 & 18.9510 & 20.2430 & 4.6872 & 62.8900 & 6.2880 & 6.3000 & 6.1500 & 6.3000 \\
\hline $\mathrm{P}_{\text {Loss }}(\mathrm{MW})$ & 21.8935 & 23.1152 & 23.7039 & 23.4480 & 23.7100 & 23.4611 & 24.5440 & 24.2655 & 24.4799 & 24.5939 & 24.2568 \\
\hline
\end{tabular}

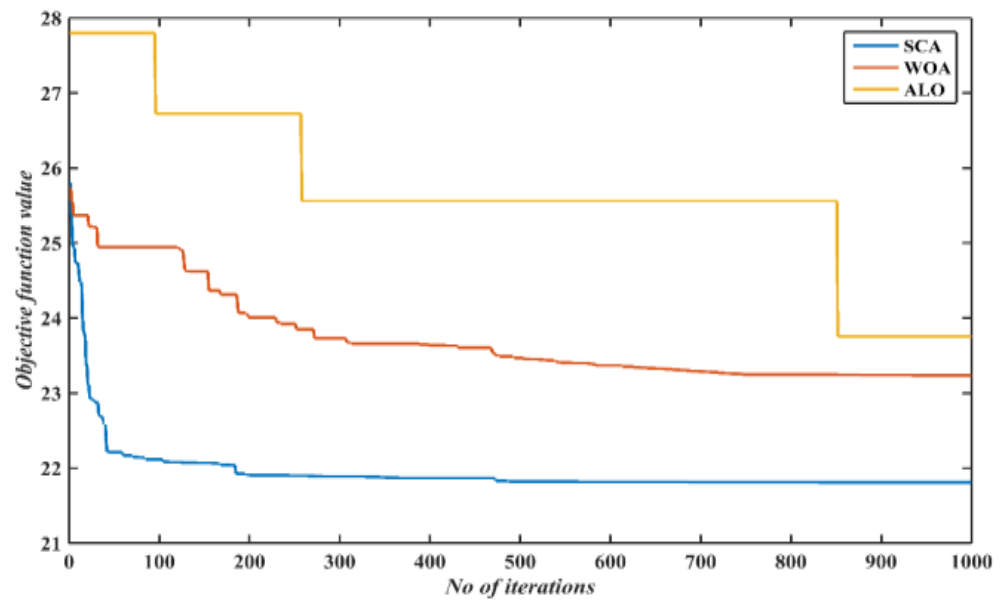

Fig. 9 Convergence characteristics of IEEE-57 bus system 
Table. 8 Best solutions of all algorithms for IEEE 57 bus system

\begin{tabular}{|c|c|c|c|c|c|}
\hline Algorithms & Best (pu) & Worst (pu) & Mean (pu) & Std.Deviation & $\% P_{\text {Save }}$ \\
\hline NLP [16] & 0.25902 & 0.30854 & 0.27858 & $1.167 \times 10^{-2}$ & 8.9934 \\
\hline CGA [16] & 0.25244 & 0.27508 & 0.26294 & $6.295 \times 10^{-3}$ & 11.3059 \\
\hline AGA [16] & 0.24565 & 0.26762 & 0.25128 & $6.006 \times 10^{-3}$ & 13.6925 \\
\hline PSO-w [16] & 0.24271 & 0.26153 & 0.24726 & $7.014 \times 10^{-3}$ & 14.7266 \\
\hline PSO-cf [16] & 0.24280 & 0.26033 & 0.24698 & $6.629 \times 10^{-3}$ & 14.6925 \\
\hline CLPSO [16] & 0.24515 & 0.24781 & 0.24673 & $9.341 \times 10^{-4}$ & 13.8669 \\
\hline SPSO-07[16] & 0.24430 & 0.25457 & 0.24752 & $2.833 \times 10^{-3}$ & 14.6925 \\
\hline L-DE [16] & 0.27813 & 0.41909 & 0.33178 & $4.707 \times 10^{-2}$ & 13.8669 \\
\hline L-SACP-DE [16] & 0.27916 & 0.36979 & 0.31033 & $3.223 \times 10^{-2}$ & 14.1647 \\
\hline L-SaDE [16] & 0.24267 & 0.24391 & 0.24311 & $4.815 \times 10^{-4}$ & 14.2815 \\
\hline SOA [16] & 0.24265 & 0.24280 & 0.24271 & $4.208 \times 10^{-5}$ & 14.7443 \\
\hline HSA [17] & 0.24906 & 0.26965 & 0.25924 & - & - \\
\hline HAS [34] & 0.23710 & 0.24272 & 0.23898 & $4.469 \times 10^{-5}$ & 16.6959 \\
\hline IHSA [34] & 0.23448 & 0.24011 & 0.23755 & $4.177 \times 10^{-5}$ & 17.6165 \\
\hline ALO (proposed) & 0.23704 & 0.24542 & 0.23753 & $4.077 \times 10^{-5}$ & 17.7170 \\
\hline WOA (proposed) & 0.23115 & 0.24315 & 0.23557 & $3.489 \times 10^{-5}$ & 18.7864 \\
\hline SCA (proposed) & 0.21894 & 0.22397 & 0.21673 & $3.178 \times 10^{-5}$ & 23.0740 \\
\hline
\end{tabular}

Table 8 shows the outcome of the solution to minimize the objective when tabulating the best reactive power dispatch solutions for this objective. Table 8 compares the SCA-based findings with other recently reported optimization techniques in the literature like NLP [16] ;CGA [16]; AGA [16]; PSO-w [16]; PSO-cf [16]; CLPSO [16] ;SPSO-07[16]; L-DE [16]; L-SACP-DE [16]; L-SaDE [16]; SOA [16]; HSA [17]; HSA [34] and IHSA [34. Also, SCA results are compared with ALO and WOA.

From Table 4, results based on SCA can be observed yielding optimum $\mathrm{P}_{\text {Loss }}$ value for this power network. In [19], the base case power loss is reported as $28.462 \mathrm{MW}$ for this test power network. The percentage save of power loss shows that a power loss reduction of $23.07 \%$ (28.462 MW to $21.894 \mathrm{MW}$ ) is achieved by using the proposed SCA method, which is the highest power loss reduction than that obtained by the other literature approaches. Comparative
Convergence profiles based on ALO, WOA and SCA for this test power system are shown in Fig. 9. It can be observed from this figure that the convergence profile for this test system is capable of the proposed SCA-based approach.

\section{Test system 3: Standard IEEE-118 bus system}

A standard IEEE 118-bus test system is considered to analyze the proposed technique for solving large and complex power systems.This case system's control varaiables have 77 proportions, i.e. the 54 generator buses, 64 load buses, 186 transmission lines, 9 transformer taps, and 14 reactive power sources. Details of the system some are given in $[19,23,25,29]$. Tables 10 and 11 , respectively [25], show the lower and upper limits of reactive power sources, voltage, and tap-setting limits. The system loads are specified as follows $\mathrm{P}_{\text {load }}=4242 \mathrm{MW}$., $\mathrm{Q}_{\text {load }}=1438 \mathrm{MVAr}$. The total power losses are as $\mathrm{P}_{\text {loss }}=132.283 \mathrm{MW}$.

Table. 9 Minimum and Maximum limits of control variables for IEEE-118 bus system

\begin{tabular}{|c|c|c|c|c|c|c|c|c|c|c|c|c|c|c|}
\hline \multicolumn{15}{|c|}{ Reactive power sources (MVAr) } \\
\hline \multicolumn{8}{|c|}{$Q_{C}^{\min }$} & \multicolumn{7}{|c|}{$Q_{C}^{\max }$} \\
\hline Bus No & 5 & 34 & 37 & 44 & 45 & 46 & 48 & 5 & 34 & 37 & 44 & 45 & 46 & 48 \\
\hline Values & -40 & 0 & -25 & 0 & 0 & 0 & 0 & 0 & 14 & 0 & 10 & 10 & 10 & 15 \\
\hline Bus No & 74 & 79 & 82 & 83 & 105 & 107 & 110 & 74 & 79 & 82 & 83 & 105 & 107 & 110 \\
\hline Values & 0 & 0 & 0 & 0 & 0 & 0 & 0 & 12 & 20 & 20 & 10 & 20 & 6 & 6 \\
\hline \multicolumn{8}{|c|}{ Generator voltages $(\mathrm{pu})$} & \multicolumn{7}{|c|}{ Transformer tap } \\
\hline \multicolumn{3}{|c|}{$V_{G}^{\min }$} & \multicolumn{5}{|c|}{$V_{G}^{\max }$} & \multicolumn{2}{|c|}{$T_{i}^{\min }$} & \multicolumn{5}{|c|}{$T_{i}^{\max }$} \\
\hline \multicolumn{3}{|c|}{0.95} & \multicolumn{5}{|c|}{1.1} & \multicolumn{2}{|c|}{0.9} & \multicolumn{5}{|c|}{1.1} \\
\hline
\end{tabular}




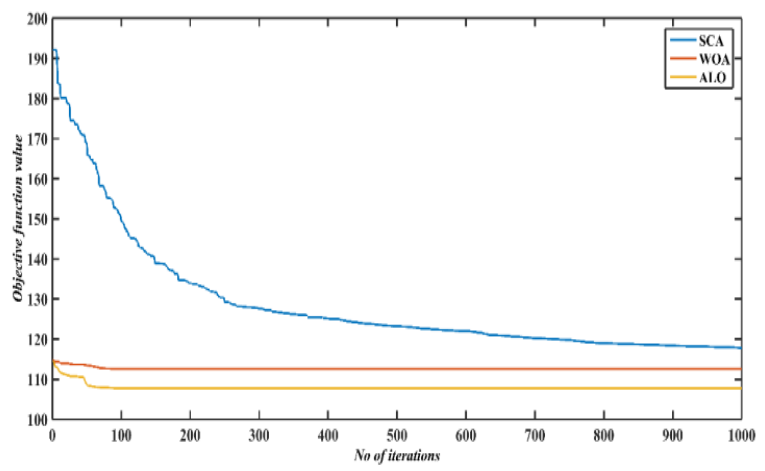

Fig. 10 Convergence characteristics of IEEE-118 bus system

Table. 10 Best control variables settings and active power loss for IEEE-118 bus system

\begin{tabular}{|c|c|c|c|c|c|c|c|c|c|}
\hline $\begin{array}{c}\text { Control } \\
\text { variables }\end{array}$ & $\begin{array}{c}S C A \\
\text { (proposed) }\end{array}$ & $\begin{array}{c}\text { WOA } \\
\text { (proposed) }\end{array}$ & $\begin{array}{c}A L O \\
\text { (proposed) }\end{array}$ & $\begin{array}{l}\text { ICA } \\
{[23]}\end{array}$ & $\begin{array}{l}\text { IWO } \\
{[23]}\end{array}$ & $\begin{array}{c}\text { MICA- } \\
\text { IWO [23] }\end{array}$ & GSA [19] & PSO[19] & CLPSO [19] \\
\hline $\mathrm{V}_{l}(\mathrm{pu})$ & 1.0846 & 1.1000 & 1.1000 & 1.0080 & 0.9978 & 1.0419 & 0.9600 & 1.0853 & 1.0332 \\
\hline $\mathrm{V}_{4}(\mathrm{pu})$ & 1.0996 & 1.0969 & 1.1000 & 1.0296 & 1.0378 & 1.0600 & 0.9620 & 1.0420 & 1.0550 \\
\hline $\mathrm{V}_{6}(\mathrm{pu})$ & 1.0992 & 1.0769 & 1.1000 & 1.0149 & 1.0189 & 1.0542 & 0.9729 & 1.0805 & 0.9754 \\
\hline $\mathrm{V}_{8}(\mathrm{pu})$ & 1.1000 & 1.1000 & 1.1000 & 1.0381 & 0.9922 & 1.0582 & 1.0570 & 0.9683 & 0.9669 \\
\hline $\mathrm{V}_{10}(\mathrm{pu})$ & 1.1000 & 1.0960 & 1.1000 & 1.0600 & 1.0245 & 1.0600 & 1.0885 & 1.0756 & 0.9811 \\
\hline $\mathrm{V}_{12}(\mathrm{pu})$ & 1.0937 & 1.0999 & 1.1000 & 1.0131 & 1.0087 & 1.0511 & 0.9630 & 1.0225 & 1.0092 \\
\hline $\mathrm{V}_{15}(\mathrm{pu})$ & 1.0872 & 1.0784 & 1.1000 & 1.0006 & 0.9804 & 1.0498 & 1.0127 & 1.0786 & 0.9787 \\
\hline $\mathrm{V}_{18}(\mathrm{pu})$ & 1.0865 & 1.0772 & 1.1000 & 0.9987 & 0.9883 & 1.0525 & 1.0069 & 1.0498 & 1.0799 \\
\hline $\mathrm{V}_{19}(\mathrm{pu})$ & 1.0986 & 1.0715 & 1.1000 & 1.0036 & 0.9862 & 1.0490 & 1.0003 & 1.0776 & 1.0805 \\
\hline $\mathrm{V}_{24}(\mathrm{pu})$ & 1.0993 & 1.0838 & 1.1000 & 1.0388 & 0.9673 & 1.0528 & 1.0105 & 1.0827 & 1.0286 \\
\hline $\mathrm{V}_{25}(\mathrm{pu})$ & 1.0965 & 1.0906 & 1.1000 & 1.0600 & 1.0515 & 1.0600 & 1.0102 & 0.9564 & 1.0307 \\
\hline $\mathrm{V}_{26}(\mathrm{pu})$ & 1.0949 & 1.0937 & 1.1000 & 1.0600 & 0.9948 & 1.0600 & 1.0401 & 1.0809 & 0.9877 \\
\hline $\mathrm{V}_{27}(\mathrm{pu})$ & 1.0938 & 1.0798 & 1.1000 & 1.0093 & 0.9829 & 1.0466 & 0.9809 & 1.0874 & 1.0157 \\
\hline $\mathrm{V}_{31}(\mathrm{pu})$ & 1.0984 & 0.9849 & 1.1000 & 0.9958 & 0.9461 & 1.0430 & 0.9500 & 0.9608 & 0.9615 \\
\hline $\mathrm{V}_{32}(\mathrm{pu})$ & 1.0968 & 0.9638 & 1.1000 & 1.0016 & 0.9532 & 1.0453 & 0.9552 & 1.1000 & 0.9851 \\
\hline $\mathrm{V}_{34}(\mathrm{pu})$ & 1.0909 & 0.9501 & 1.1000 & 1.0267 & 1.0099 & 1.0600 & 0.9910 & 0.9611 & 1.0157 \\
\hline $\mathrm{V}_{36}(\mathrm{pu})$ & 1.0979 & 0.9681 & 1.1000 & 1.0257 & 1.0019 & 1.0584 & 1.0091 & 1.0367 & 1.0849 \\
\hline $\mathrm{V}_{40}(\mathrm{pu})$ & 1.0869 & 0.9721 & 1.1000 & 1.0181 & 0.9886 & 1.0384 & 0.9505 & 1.0914 & 0.9830 \\
\hline $\mathrm{V}_{42}(\mathrm{pu})$ & 1.1000 & 1.0610 & 1.1000 & 1.0285 & 0.9559 & 1.0398 & 0.9500 & 0.9701 & 1.0516 \\
\hline $\mathrm{V}_{46}(\mathrm{pu})$ & 1.0939 & 0.9890 & 1.1000 & 1.0409 & 1.0205 & 1.0470 & 0.9814 & 1.0390 & 0.9754 \\
\hline $\mathrm{V}_{49}(\mathrm{pu})$ & 1.0958 & 1.0083 & 1.1000 & 1.0535 & 1.0528 & 1.0600 & 1.0444 & 1.0836 & 0.9838 \\
\hline $\mathrm{V}_{54}(\mathrm{pu})$ & 1.0921 & 0.9935 & 1.1000 & 1.0291 & 1.0146 & 1.0388 & 1.0379 & 0.9764 & 0.9637 \\
\hline $\mathrm{V}_{55}(\mathrm{pu})$ & 1.0999 & 0.9825 & 1.1000 & 1.0285 & 1.0149 & 1.0380 & 0.9907 & 1.0103 & 0.9716 \\
\hline $\mathrm{V}_{56}(\mathrm{pu})$ & 1.0959 & 1.0218 & 1.1000 & 1.0286 & 1.0162 & 1.0382 & 1.0333 & 0.9536 & 1.0250 \\
\hline $\mathrm{V}_{59}(\mathrm{pu})$ & 1.0893 & 1.0441 & 1.1000 & 1.0478 & 1.0046 & 1.0600 & 1.0099 & 0.9672 & 1.0003 \\
\hline $\mathrm{V}_{61}(\mathrm{pu})$ & 1.1000 & 1.0487 & 1.1000 & 1.0406 & 1.0468 & 1.0600 & 1.0925 & 1.0938 & 1.0771 \\
\hline $\mathrm{V}_{62}(\mathrm{pu})$ & 1.1000 & 1.0964 & 1.1000 & 1.0346 & 1.0547 & 1.0559 & 1.0393 & 1.0978 & 1.0480 \\
\hline $\mathrm{V}_{65}(\mathrm{pu})$ & 1.1000 & 1.0977 & 1.1000 & 1.0600 & 1.0547 & 1.0600 & 0.9998 & 1.0892 & 0.9684 \\
\hline $\mathrm{V}_{66}(\mathrm{pu})$ & 1.0969 & 1.0624 & 1.1000 & 1.0600 & 1.0572 & 1.0600 & 1.0355 & 1.0861 & 0.9648 \\
\hline $\mathrm{V}_{69}(\mathrm{pu})$ & 1.0972 & 1.0798 & 1.1000 & 1.0600 & 1.0599 & 1.0600 & 1.1000 & 0.9665 & 0.9574 \\
\hline $\mathrm{V}_{70}(\mathrm{pu})$ & 1.0909 & 1.1000 & 1.1000 & 1.0371 & 1.0297 & 1.0377 & 1.0992 & 1.0783 & 0.9765 \\
\hline $\mathrm{V}_{72}(\mathrm{pu})$ & 1.0934 & 1.0209 & 1.1000 & 1.0390 & 0.9832 & 1.0430 & 1.0014 & 0.9506 & 1.0243 \\
\hline $\mathrm{V}_{73}(\mathrm{pu})$ & 1.0932 & 1.0082 & 1.1000 & 1.0411 & 1.0030 & 1.0374 & 1.0111 & 0.9722 & 0.9651 \\
\hline $\mathrm{V}_{74}(\mathrm{pu})$ & 1.0919 & 1.0350 & 1.1000 & 1.0235 & 1.0239 & 1.0275 & 1.0476 & 0.9713 & 1.0733 \\
\hline $\mathrm{V}_{76}(\mathrm{pu})$ & 1.0986 & 1.0520 & 1.1000 & 1.0107 & 0.9474 & 1.0253 & 1.0211 & 0.9602 & 1.0302 \\
\hline $\mathrm{V}_{77}(\mathrm{pu})$ & 1.0972 & 1.0748 & 1.1000 & 1.0297 & 1.0311 & 1.0473 & 1.0187 & 1.0781 & 1.0275 \\
\hline $\mathrm{V}_{80}(\mathrm{pu})$ & 1.0902 & 1.1000 & 1.1000 & 1.0389 & 1.0510 & 1.0600 & 1.0462 & 1.0788 & 0.9857 \\
\hline $\mathrm{V}_{85}(\mathrm{pu})$ & 1.1000 & 1.0934 & 1.1000 & 1.0514 & 1.0070 & 1.0600 & 1.0491 & 0.9568 & 0.9836 \\
\hline $\mathrm{V}_{87}(\mathrm{pu})$ & 1.0952 & 1.0565 & 1.1000 & 1.0417 & 0.9421 & 1.0600 & 1.0426 & 0.9642 & 1.0882 \\
\hline $\mathrm{V}_{89}(\mathrm{pu})$ & 1.0973 & 1.0465 & 1.1000 & 1.0600 & 1.0562 & 1.0600 & 1.0955 & 0.9748 & 0.9895 \\
\hline $\mathrm{V}_{90}(\mathrm{pu})$ & 1.0996 & 1.0879 & 1.1000 & 1.0340 & 1.0389 & 1.0445 & 1.0417 & 1.0248 & 0.9905 \\
\hline $\mathrm{V}_{91}(\mathrm{pu})$ & 1.0926 & 1.0758 & 1.1000 & 1.0374 & 1.0198 & 1.0496 & 1.0032 & 0.9615 & 1.0288 \\
\hline
\end{tabular}


Reactive Power Control using Sine Cosine Algorithm for Active Power Loss Minimization with Voltage Profile Enhancement

\begin{tabular}{|c|c|c|c|c|c|c|c|c|c|}
\hline $\mathrm{V}_{92}(\mathrm{pu})$ & 1.0992 & 1.0468 & 1.1000 & 1.0470 & 1.0167 & 1.0600 & 1.0927 & 0.9568 & 0.9760 \\
\hline $\mathrm{V}_{99}(\mathrm{pu})$ & 1.0993 & 1.0245 & 1.1000 & 1.0309 & 1.0588 & 1.0560 & 1.0433 & 0.9540 & 1.0880 \\
\hline $\mathrm{V}_{100}(\mathrm{pu})$ & 1.0937 & 1.0029 & 1.1000 & 1.0257 & 1.0332 & 1.0600 & 1.0786 & 0.9584 & 0.9617 \\
\hline $\mathrm{V}_{103}(\mathrm{pu})$ & 1.0913 & 1.0110 & 1.1000 & 1.0113 & 1.0141 & 1.0600 & 1.0266 & 1.0162 & 0.9611 \\
\hline $\mathrm{V}_{104}(\mathrm{pu})$ & 1.0903 & 1.0215 & 1.1000 & 0.9949 & 1.0063 & 1.0518 & 0.9808 & 1.0992 & 1.0125 \\
\hline $\mathrm{V}_{105}(\mathrm{pu})$ & 1.0973 & 0.9778 & 1.1000 & 0.9923 & 0.9945 & 1.0517 & 1.0163 & 0.9694 & 1.0684 \\
\hline $\mathrm{V}_{107}(\mathrm{pu})$ & 1.0992 & 0.9643 & 1.1000 & 0.9800 & 0.9487 & 1.0389 & 0.9987 & 0.9656 & 0.9769 \\
\hline $\mathrm{V}_{110}(\mathrm{pu})$ & 1.0881 & 0.9650 & 1.1000 & 0.9984 & 1.0441 & 1.0508 & 1.0218 & 1.0873 & 1.0414 \\
\hline $\mathrm{V}_{111}(\mathrm{pu})$ & 1.0987 & 1.0598 & 1.1000 & 1.0080 & 0.9743 & 1.0600 & 0.9852 & 1.0375 & 0.9790 \\
\hline $\mathrm{V}_{112}(\mathrm{pu})$ & 1.1000 & 1.0311 & 1.1000 & 0.9823 & 0.9863 & 1.0358 & 0.9500 & 1.0920 & 0.9764 \\
\hline $\mathrm{V}_{113}(\mathrm{pu})$ & 1.1000 & 1.1000 & 1.1000 & 0.9786 & 0.9771 & 1.0600 & 0.9764 & 1.0753 & 0.9721 \\
\hline $\mathrm{V}_{116}(\mathrm{pu})$ & 1.0862 & 1.0762 & 1.1000 & 1.0473 & 1.0566 & 1.0600 & 1.0372 & 0.9594 & 1.0330 \\
\hline $\mathrm{T}_{5-8}$ & 1.0516 & 1.0508 & 0.9855 & 0.9900 & 1.0400 & 1.0000 & 1.0659 & 1.0112 & 1.0045 \\
\hline $\mathrm{T}_{25-26}$ & 1.0894 & 0.9000 & 0.9869 & 1.1000 & 0.9900 & 1.1000 & 0.9534 & 1.0906 & 1.0609 \\
\hline $\mathrm{T}_{17-30}$ & 1.0306 & 1.0592 & 0.9869 & 1.0300 & 1.0800 & 0.9900 & 0.9328 & 1.0033 & 1.0008 \\
\hline $\mathrm{T}_{37-38}$ & 1.0938 & 1.0929 & 0.9825 & 1.0100 & 1.0400 & 0.9800 & 1.0884 & 1.0000 & 1.0093 \\
\hline $\mathrm{T}_{59-63}$ & 1.0614 & 1.1000 & 0.9821 & 0.9800 & 0.9500 & 0.9800 & 1.0579 & 1.0080 & 0.9922 \\
\hline $\mathrm{T}_{61-64}$ & 1.0970 & 1.0446 & 0.9869 & 1.0100 & 1.0200 & 1.0000 & 0.9493 & 1.0326 & 1.0074 \\
\hline $\mathrm{T}_{65-66}$ & 1.0919 & 0.9000 & 0.9840 & 0.9400 & 0.9500 & 0.9000 & 0.9975 & 0.9443 & 1.0611 \\
\hline $\mathrm{T}_{68-69}$ & 1.0940 & 1.0905 & 0.9869 & 0.9800 & 0.9300 & 0.9500 & 0.9887 & 0.9067 & 0.9307 \\
\hline $\mathrm{T}_{80-81}$ & 1.0887 & 0.9000 & 0.9869 & 0.9900 & 1.0300 & 0.9900 & 0.9801 & 0.9673 & 0.9578 \\
\hline $\mathrm{Q}_{\mathrm{c5}}$ (MVAr) & -10.8225 & -14.4695 & -9.8636 & $\begin{array}{c}- \\
0.0732 \\
\end{array}$ & -0.2064 & -0.4 & 0.0000 & 0.0000 & 0.0000 \\
\hline $\mathrm{Q}_{\mathrm{C} 34}(\mathrm{MVAr})$ & 12.3162 & 2.4322 & 13.3826 & 0.0477 & 0.1382 & 0.1400 & 7.4600 & 9.3639 & 11.7135 \\
\hline $\mathrm{Q}_{\mathrm{C} 37}(\mathrm{MVAr})$ & -12.9499 & -23.6278 & 0.0000 & $\begin{array}{c}- \\
0.1268 \\
\end{array}$ & -0.0117 & 0.0000 & 0.0000 & 0.0000 & 0.0000 \\
\hline $\mathrm{Q}_{\mathrm{c} 44}(\mathrm{MVAr})$ & 7.1527 & 0.0000 & 8.9827 & 0.0000 & 0.0081 & 0.0429 & 6.0700 & 9.3078 & 9.8932 \\
\hline $\mathrm{Q}_{\mathrm{C} 45}(\mathrm{MVAr})$ & 6.1718 & 5.3532 & 9.7600 & 0.0505 & 0.0053 & 0.0073 & 3.3300 & 8.6428 & 9.4169 \\
\hline $\mathrm{Q}_{\mathrm{c} 46}(\mathrm{MVAr})$ & 6.9794 & 8.2046 & 4.3833 & 0.0669 & 0.0199 & 0.0697 & 6.5100 & 8.9462 & 2.6719 \\
\hline $\mathrm{Q}_{\mathrm{c} 48}(\mathrm{MVAr})$ & 9.5686 & 15.0000 & 14.3206 & 0.0321 & 0.1461 & 0.0368 & 4.4700 & 11.8092 & 2.8546 \\
\hline $\mathrm{Q}_{\mathrm{c} 74}(\mathrm{MVAr})$ & 8.9064 & 9.0147 & 11.4601 & 0.0000 & 0.0081 & 0.0000 & 9.7200 & 4.6132 & 0.5471 \\
\hline $\mathrm{Q}_{\mathrm{c} 79}(\mathrm{MVAr})$ & 16.6085 & 15.1698 & 19.1021 & 0.0000 & 0.1537 & 0.0000 & 14.2500 & 10.5923 & 14.8532 \\
\hline $\mathrm{Q}_{\mathrm{c} 82}(\mathrm{MVAr})$ & 5.5913 & 4.9987 & 18.7492 & 0.0000 & 0.0037 & 0.0000 & 17.4900 & 16.4544 & 19.4270 \\
\hline $\mathrm{Q}_{\mathrm{C} 83}(\mathrm{MVAr})$ & 7.2092 & 2.6740 & 8.9635 & 0.0260 & 0.0367 & 0.0000 & 4.2800 & 9.6325 & 6.9824 \\
\hline $\mathrm{Q}_{\mathrm{c} 105}(\mathrm{MVAr})$ & 9.2179 & 17.6632 & 19.1208 & 0.1995 & 0.0265 & 0.0001 & 12.0400 & 8.9513 & 9.0291 \\
\hline $\mathrm{Q}_{\mathrm{c} 107}(\mathrm{MVAr})$ & 1.3906 & 3.0503 & 0.1786 & 0.0235 & 0.0587 & 0.0016 & 2.2600 & 5.0426 & 4.9926 \\
\hline $\mathrm{Q}_{\mathrm{c} 110}(\mathrm{MVAr})$ & 3.3235 & 5.0448 & 5.7373 & 0.0483 & 0.0486 & 0.0002 & 2.9400 & 5.5319 & 2.2086 \\
\hline$P_{\text {Loss }}(M W)$ & 107.8154 & 110.8362 & 130.6457 & 118.32 & 137.30 & 114.05 & 127.760 & 131.990 & 130.960 \\
\hline
\end{tabular}

Table. 11 Best solutions of all algorithms for IEEE 118 bus system

\begin{tabular}{|c|c|c|c|c|c|}
\hline Algorithms & Best (pu) & Worst $(p u)$ & Mean (pu) & Std. Dev & \% Psave \\
\hline ICA [23] & 1.18322 & 1.21527 & 1.18970 & $6.4261 \times 10^{-3}$ & 11.27 \\
\hline IWO [23] & 1.37295 & 1.56288 & 1.45752 & $9.4227 \times 10^{-2}$ & -2.95 \\
\hline MICA-IWO [23] & 1.14046 & 1.14976 & 1.14448 & $2.4288 \times 10^{-4}$ & 14.48 \\
\hline RGA [23] & 1.22140 & 1.26696 & 1.24089 & $1.791 \times 10^{-2}$ & - \\
\hline CMAES [23] & 1.19275 & 1.21860 & 1.20854 & $8.62 \times 10^{-3}$ & - \\
\hline MOPSO [23] & 1.19581 & - & - & - & - \\
\hline MNSGA-II [23] & 1.19279 & - & - & - & - \\
\hline DMSDE [23] & 1.15370 & - & 1.16840 & $8.787 \times 10^{-3}$ & 13.4879 \\
\hline PSO-cf [23] & 1.15821 & - & 1.18827 & $1.7248 \times 10^{-2}$ & 13.1496 \\
\hline PSO-w [23] & 1.15833 & - & 1.20575 & $2.3574 \times 10^{-2}$ & 13.1408 \\
\hline AGA [23] & 1.23964 & - & 1.27827 & $2.0613 \times 10^{-2}$ & 17.0438 \\
\hline MVMO [23] & 1.15793 & 1.19358 & 1.16820 & $7.682 \times 10^{-3}$ & - \\
\hline PSO [23] & 1.20897 & 1.35372 & 1.25487 & $3.1634 \times 10^{-2}$ & - \\
\hline JADE [23] & 1.19161 & 1.32035 & 1.22677 & $3.0467 \times 10^{-2}$ & - \\
\hline JADE-vPS [23] & 1.19201 & 1.33344 & 1.25575 & $3.8943 \times 10^{-2}$ & - \\
\hline CGA [23] & 1.39415 & 1.49009 & 1.43548 & $2.6026 \times 10^{-2}$ & - \\
\hline AGA [23] & 1.24209 & 1.31078 & 1.27701 & $1.836 \times 10^{-2}$ & - \\
\hline PSO-w [23] & 1.15815 & 1.18214 & 1.16771 & $6.8971 \times 10^{-3}$ & - \\
\hline
\end{tabular}




\begin{tabular}{|l|l|l|l|l|l|}
\hline PSO-cf [23] & 1.15642 & 1.18058 & 1.16202 & $6.1864 \times 10^{-3}$ & - \\
\hline CLPSO [23] & 1.23152 & 1.25499 & 1.24080 & $6.4325 \times 10^{-3}$ & - \\
\hline SPSO-07 [23] & 1.39275 & 1.50244 & 1.46266 & $2.653 \times 10^{-2}$ & - \\
\hline L-DE [23] & 1.51009 & 1.76614 & 1.62315 & $8.2443 \times 10^{-2}$ & - \\
\hline L-SACP-DE [23] & 1.41799 & 1.76812 & 1.60679 & $1.0643 \times 10^{-1}$ & - \\
\hline L-SaDE [23] & 1.16906 & 1.18862 & 1.17598 & $5.4041 \times 10^{-3}$ & - \\
\hline SOA [12] & 1.14950 & 1.16347 & 1.15674 & $3.5908 \times 10^{-3}$ & - \\
\hline ALO (proposed) & 1.30457 & 1.32023 & 1.31430 & $4.4041 \times 10^{-3}$ & 13.803 \\
\hline WOA (proposed) & 1.10836 & 1.11017 & 1.10573 & $5.3434 \times 10^{-3}$ & 16.210 \\
\hline SCA (proposed) & $\mathbf{1 . 0 7 8 1 5}$ & $\mathbf{1 . 0 8 4 7 6}$ & $\mathbf{1 . 0 7 5 6 4}$ & $\mathbf{2 . 7 6 7 5 \times 1 0 ^ { - 3 }}$ & $\mathbf{1 8 . 4 9 6}$ \\
\hline
\end{tabular}

SCA based reactive power dispatch schedule for the trial system of power loss minimization objective is presented in Table 10 and the results obtained are compared to ICA [23]; IWO [23]; MICA-IWO [23]; GSA [19]; PSO [19]; CLPSO [19], ALO and WOA. This table shows that compared to other algorithms, the SCA yields optimal loss. Table 11 records the statistical comparison of effects obtained from SCA with existing results presented in the literature. From this table, it was noted that the standard deviation and median values are rather acceptable to SCA. From this Fig. 10 , the respectable convergence profile of the SCA can be noted by its ability to reach the nearly optimal solution.

\section{CONCLUSION}

The optimal problem of reactive power dispatch is cast as a nonlinear problem of optimization with the power system's inequality and equality limitations. Several methods of optimization have solved it, and on this ground the analysis algorithms was carried out on the IEEE 14/57-bus and large 118-bus systems to obtain reactive power optimization. SCA has been one of different methods of optimization that has more beneficial effects. A comparison was performed on the results obtained from ALO, WOA and various literatures. The proposed SCA is thus capable of solving the problem of reactive power dispatch quickly and effectively and can be considered a promising expectation for future research.

\section{REFERENCES}

1. Dommel, H. W. and Tinney, W. F., Optimal power flow solutions. IEEE Transactions on Power Apparatus and Systems, 1968, 87, 18661876.

2. Venikov, V A Cybernetics in electrical power systems, M I R Publishers, Moscow, 1978

3. Mamandur, K R C and Chenoweth, R D 'Optimal control for reactive power flow for improvements in voltage profiles and for real power losses minimization', IEEE Transactions on Power Apparatus and Systems PAS-100 (1981) pp 3185-3193. large power network using the decomposition approach. In: IEEE trans power syst, vol. 5, no. 2; 1990. p. 428-35.

5. Momoh JA, El-Hawary ME, Adapa R. A review of selected optimal power flow literature to 1993. II. Newton, linear programming and interior point methods. IEEE Trans Power Syst 1999; 14(1):105-11.

6. Granville S. Optimal reactive dispatch through interior point methods. In: IEEE trans power syst, vol. 9, no. 1; 1994. p. 136-46.

7. Momoh JA, Adapa R, El-Hawary ME. A review of selected optimal power flow literature to 1993. I. Nonlinear and quadratic programming approaches. IEEE Trans Power Syst 1999; 14(1):96-104.

8. Yan, W., Lu, S., Yu, D.C., 2004. A novel optimal reactive power dispatch method based on an improved hybrid evolutionary programming technique. IEEE Trans. Power Syst. 19 (2), 913-918.

9. Zhao, B., Guo, C.X., Cao, Y.J., 2005. A multi-agent-based particle swarm optimization approach for optimal reactive power dispatch. IEEE Trans. Power Syst. 20 (2), 1070-1078. and comparison has been carried out. The implementation of

4. Deeb N, Shahedipour SM. Linear reactive power optimization in a

10. Varadarajan, M., Swarup, K.S., 2008. Differential evolution approach for optimal reactive power dispatch. Applied Soft Computing, 8(4), September 2008, 1549-1561.

11. Ying Li, Yijia Cao, Zhaoyan Liu, Yi Liu, Quanyuan Jiang., 2009. Dynamic optimal reactive power dispatch based on parallel particle swarm optimization algorithm. Computers and Mathematics with Applications, 57, 1835-1842.

12. Chaohua Daia,Weirong Chen, Yunfang Zhu, Xuexia Zhang., 2009. Reactive power dispatch considering voltage stability with seeker optimization algorithm. Electric Power Systems Research, 79,14621471.

13. K. Mahadevan, P.S. Kannan., 2010. Comprehensive learning particle swarm optimization for reactive power dispatch. Applied Soft Computing, 10, 641-652.

14. Xuexia Zhang, Weirong Chen, Chaohua Dai, Wenzhao Cai., 2010. Dynamic multi-group self-adaptive differential evolution algorithm for reactive power optimization. Electrical Power and Energy Systems, 32, 351-357.

15. A.H. Khazali, M. Kalantar., 2011. Optimal reactive power dispatch based on harmony search algorithm. Electrical Power and Energy Systems, 33, 684-692.

16. S. Jeyadevi, S. Baskar, C.K. Babulal, M. Willjuice Iruthayarajan, 2011. Solving multiobjective optimal reactive power dispatch using modified NSGA-II. Electrical Power and Energy Systems, 33, 219-228.

17. Roy, P.K., Mandal, B., Bhattacharya, K., 2012. Gravitational search algorithm based optimal reactive power dispatch for voltage stability enhancement. Electr. Power Compon. Syst 40 (9), 956-976.

18. Xu, Y., Zhang, W., Liu, W., Ferrese, F., 2012. Multiagent-based reinforcement learning for optimal reactive power dispatch. IEEE Trans. Syst. Man Cybern. Part B Cybern. 42 (6), 1742-1751.

19. S. Duman., Y. Sonmez., U. Guvenc. , N. Yorukeren, 2012. Optimal reactive power dispatch using a gravitational search algorithm. IET Gener. Transm. Distrib., Vol. 6, Iss. 6, pp. 563-576

20. R. Mallipeddi, S. Jeyadevi, P.N. Suganthan, S. Baskar, 2012. Efficient constraint handling for optimal reactive power dispatch problems. Electrical Power and Energy Systems, 5, 28-36.

21. Barun Mandal, Provas Kumar Roy, 2013. Optimal reactive power dispatch using quasi-oppositional teaching learning based optimization. Electrical Power and Energy Systems, 53, 123-134.

22. Barun Mandal, Provas Kumar Roy, 2013. Multi-objective optimal reactive power dispatch considering voltage stability in power systems using HFMOEA. Engineering Applications of Artificial Intelligence, 26, 390-404.

23. Mojtaba Ghasemi, Sahand Ghavidel, Mohammad Mehdi Ghanbarian, Amir Habibi, 2014. A new hybrid algorithm for optimal reactive power dispatch problem with discrete and continuous control variables. Applied Soft Computing 22, 126-140.

24. Binod Shaw, V. Mukherjee, S.P. Ghoshal, 2014. Solution of reactive power dispatch of power systems by an opposition-based gravitational search algorithm. Electrical Power and Energy Systems, 55, 29-40.

25. Abhishek Rajan, T. Malakar, 2015. Optimal reactive power dispatch using hybrid Nelder-Mead simplex based firefly algorithm. Electrical Power and Energy Systems, 66, 9-24.

26. Mojtaba Ghasemi, Mahdi Taghizadeh, Sahand Ghavidel, Jamshid Aghaei, Abbas Abbasian, 2015. Solving optimal reactive power dispatch problem using a novel teaching-learning-based optimization algorithm. Electrical Power and Energy Systems, 39, 100-108. 


\section{Enhancement}

27. Mehdi Mehdinejad, Behnam Mohammadi-Ivatloo, Reza DadashzadehBonab, Kazem Zare, 2016. Solution of optimal reactive power dispatch of power systems using hybrid particle swarm optimization and imperialist competitive algorithms. Electrical Power and Energy Systems, 83, 104-116

28. Chandragupta Mauryan KUPPAMUTHU SIVALINGAM, Subramanian RAMACHANDRAN, Purrnimaa Shiva Sakthi RAJAMANI, 2017. Reactive power optimization in a power system network through metaheuristic algorithms. Turk J Elec Eng \& Comp Sci, 25, 4615-4623.

29. Kasem Nuaekaew, Pramin Artrit, Nantiwat Pholdee, Sujin Bureerat, 2017. Optimal reactive power dispatch problem using a two-archive multi-objective grey wolf optimizer. Expert Systems with Applications, 87(30), 79-89.

30. Xiaoshun Zhang, Tao Yu, Bo Yang, Lefeng Cheng, 2017. Accelerating bio-inspired optimizer with transfer reinforcement learning for reactive power optimization. Knowledge-Based Systems, 116, 26-38.

31. Khaled ben oualid Medania, Samir Sayaha Abdelghani Bekrarb, 2018. Whale optimization algorithm based optimal reactive power dispatch: A case study of the Algerian power system. Electric Power Systems Research,163, Part B, 696-705.

32. SK. Mahammad Shareef, R. Srinivasa Rao, 2018. Optimal reactive power dispatch under unbalanced conditions using hybrid swarm intelligence. Computers and Electrical Engineering, 69,183-193.

33. HOTAKA YOSHIDA, YOSHIKAZU FUKUYAMA, 2018. Parallel Multipopulation Differential Evolutionary Particle Swarm Optimization for Voltage and Reactive Power Control. Electrical Engineering in Japan, Vol. 204, No. 3, 31-40.

34. D. Karthikaikannan, G. Ravi, 2018. Optimal reactive power dispatch considering multi-type FACTS devices using harmony search algorithms, Automatika, 59:3, 303-314.

35. Mirjalili S. SCA: a sine cosine algorithm for solving optimization problems. Knowledge Based Systems 2016; 96:120-33.

36. MATLAB Release R2015b. Natick (MA, USA): The Mathworks Inc.

37. Zimmerman RD, Murillo-S' anchez CE. MATPOWER, a MATLAB power system simulation package.<http://www.pserc.cornell.edu/matpower/manual.pdf $>$;Septem ber 2007. 